\title{
A Cross-Sectional Study on University Students' Knowledge, Attitudes, and Practices Toward COVID-19 in the United Arab Emirates
}

\author{
Hayder Hasan, ${ }^{1,2 *}$ Veena Raigangar, ${ }^{2,3 *}$ Tareq Osaili, ${ }^{1,2,4}$ Noorieh E. Neinavaei, ${ }^{3}$ Amin N. Olaimat,,${ }^{5}$ and Iman Aolymat ${ }^{6}$ \\ ${ }^{1}$ Department of Clinical Nutrition and Dietetics, College of Health Sciences, University of Sharjah, Sharjah, United Arab Emirates; ${ }^{2}$ Research \\ Institute of Medical and Health Sciences, University of Sharjah, Sharjah, United Arab Emirates; ${ }^{3}$ Department of Physiotherapy, College of Health \\ Sciences, University of Sharjah, Sharjah, United Arab Emirates; ${ }^{4}$ Department of Nutrition and Food Technology, Faculty of Agriculture, Jordan \\ University of Science and Technology, Irbid, Jordan; ${ }^{5}$ Department of Clinical Nutrition and Dietetics, Faculty of Applied Medical Sciences, The \\ Hashemite University, Zarqa, Jordan; ${ }^{6}$ Department of Basic Medical Sciences, Faculty of Medicine, The Hashemite University, Zarqa, Jordan
}

Abstract. The unprecedented coronavirus pandemic is hitting the whole world, including the United Arab Emirates. Public awareness and adherence to the recommendations play a major role in managing a crisis of this magnitude which is largely affected by knowledge, attitudes, and practices (KAP). Hence, the aim of this study was to assess COVID19-related KAP of the University of Sharjah (UOS) students and compare between health-related (HR) and non-HR (NHR) majors. A cross-sectional study was conducted in May 2020 in which 1,012 (481 health-related and 531 NHR) students participated via an online KAP questionnaire. The students' sociodemographic characteristics and sources of information were also recorded, and data were analyzed. Students were aged 20-25 years, with an overall knowledge score of $72.4 \%$, and the main source of their information was the Internet and social media (85.2\%). Those in HR majors had a higher knowledge score $(76 \%)$ than those in NHR students $(69 \%)$. Regarding attitudes, both HR and NHR students demonstrated comparable and positive attitudes to curb the spread. With respect to practices, more NHR students used masks (92.3\%), almost all the time than HR students (88.4\%). HR students (99.4\%) avoided crowded places and practiced social distancing more than NHR students (99.4\% versus $97.4 \%$ and $97.7 \%$ versus $93.2 \%$, respectively). In conclusion, UOS students demonstrated adequate knowledge, and possessed good attitudes and low-risk practices toward prevention of COVID-19. It is recommended that universities including UOS continue to use digital university communication platforms to regularly disseminate vital information in such emergencies.

\section{INTRODUCTION}

Currently, the unprecedented coronavirus pandemic is hitting the whole world, including the United Arab Emirates (UAE). Coronaviruses are a large family of viruses that cause illnesses ranging from common cold to more severe diseases. ${ }^{1}$ There are several strains of this family, known to infect animals from different species. Previously, only two of them were found to infect humans, SARS-CoV ${ }^{2}$ and Middle East respiratory syndrome. ${ }^{3}$ However, in December 2019, there was an outbreak of a new disease in Wuhan city, China. It was later identified that the highly contagious disease, called COVID-19, was caused by a novel member of the family named SARS-COV-2. ${ }^{4}$ The virus soon spread to more than 200 countries and was declared as a global pandemic in March 2020 by the WHO. ${ }^{5}$

To date, there have been 29.5 million confirmed cases of COVID-19, including 932 thousands deaths reported worldwide. $^{6}$ In the UAE, the first case was reported on January 29 , $2020,{ }^{7}$ and there are 82,000 cases diagnosed with 402 deaths and 71,500 recoveries till September $16,2020 .^{8}$

Substantial efforts have been made by researchers all over the world to develop a drug or vaccine that can cure this disease, but, unfortunately, there has not been any success yet, and infected patients continue to receive symptomatic treatment only.

\footnotetext{
*Address correspondence to Veena Raigangar, Department of Physiotherapy, College of Health Sciences, University of Sharjah, University City Road, University City, P.O. Box 27272, Sharjah, United Arab Emirates, E-mail: veena@sharjah.ac.ae or Hayder Hasan, Department of Clinical Nutrition and Dietetics, College of Health Sciences, University of Sharjah, University City Road, University City, P.O. Box 27272, Sharjah, United Arab Emirates, E-mail: haidarah@ sharjah.ac.ae.
}

The symptoms of the disease range from mild (such as fever, cough, and shortness of breath) to severe (such as pneumonia, SARS, and kidney failure). ${ }^{9}$ The battle against COVID-19 is still ongoing, and almost all countries implemented preventive measures such as strict infection control and partial/complete lockdown to curb the virus and "flatten the curve." In the UAE, the lockdown took effect from the 22nd of March with partial movement restrictions for elderly and children younger than 12 years at the time of conducting the study. ${ }^{10}$

Public awareness and adherence to the recommendations play a major role in managing a crisis of this magnitude. Ways of preventing, managing, and minimizing the spread of COVID-19 have been discussed around the world. Current guidelines stress the importance of cleaning/washing hands, keeping social distance of at least $1 \mathrm{~m}$, avoiding crowded places, avoiding touching the mouth and nose, and practicing respiratory hygiene; those with cough and other medical difficulties have been asked to seek medical attention. ${ }^{1,9}$ In addition, the CDC recommends covering the mouth and nose while coughing and sneezing, followed by immediate disinfection. ${ }^{11}$ The UAE had also issued a set of guidelines and preventive measures to fight the spread of COVID-19. ${ }^{9}$

The University of Sharjah (UOS) is located in Sharjah, one of the seven Emirates. It is one of the largest universities in the UAE, with a population of 15,000 students, 14 colleges, and more than 30 majors. There are mainly Arab and Emirati students who are resident in the UAE and/or Gulf Cooperation Council primarily. These students form a very important part of the young community and might influence the health and wellbeing of their families and friends. Furthermore, this population is the most socially active, both on social media and outside in the community, making them more vulnerable to contracting COVID-19 infection. During the time of the 
study, the population mainly visiting community spaces such as malls were young adults or the middle-aged working population because of the partial lockdown. ${ }^{12}$ Furthermore, the students from early March had all their classes shifted to the online mode, which reflected a new learning experience for the students. ${ }^{13}$ Also, information regarding COVID-19 was disseminated via online channels, including university website, Linkedln, and Facebook pages. ${ }^{14-16}$ Because of the fact that these students have constant access to this information, it is important to evaluate if they are paying attention and adopting the information shared with them. Hence, assessment of their knowledge, attitudes, and practices (KAP) is crucial. Therefore, the aim of this study was to assess the KAP of the university students, as they represent a special part of the community with more autonomy but insufficient life experience which may impact their risk and that of others of COVID-19. Furthermore, comparing students from health-related (HR) and non-health-related (NHR) majors may be interesting to highlight similarities and/or differences in these population groups.

\section{MATERIALS AND METHODS}

This cross-sectional survey was conducted during the partial lockdown in the UAE in the first 2 weeks of May 2020. A non-probability convenience sample included current students from the 14 colleges of the UOS who were invited to participate in the study. Because there was no previously published prevalence data related to COVID-19 in the UAE, sample size calculations were based on the assumption that the probability of having good knowledge, positive attitudes, and good practices toward preventing disease caused by coronavirus was $50 \%,{ }^{17}$ at $\mathrm{Cl}$ of $95 \%$, with a precision of $5 \%$; using this, the calculated sample size $(N)$ was 384 . To have a good representative sample from the different majors at the UOS and account for incomplete surveys, the questionnaire was sent by email to 1,300 students. By the end of the 2-week time limit to respond to the survey, 1,012 students responded and were included in the study. This sample size is 3-fold larger than that required (384 students).

A bilingual (Arabic and English) web-based questionnaire was sent to the students via a bulk email from the registration department as well as through a link on university digital platforms. The students were informed about the nature of the study and had the right to refuse participating in the study without any consequences. Those who were interested in participation had to grant permission for the data generated from their entries, and only then, they can proceed to fill out the questionnaire. The study protocol was approved by the Research and Ethics Committee at the UOS (REC-20-0502-01).

The questionnaire was prepared based on the available information on the websites of the European and American Centers for Disease Control (ECDC and CDC, respectively) and the $\mathrm{WHO}$. The questionnaire was reviewed by five academic experts in the field and revised based on their comments. The questionnaire was pretested on 40 students selected randomly from different colleges, and none of the respondents had comments that needed to be considered. The questionnaire included multiple-choice questions intended to assess the participants' 1) sociodemographic characteristics, 2) knowledge, 3) attitudes, and 4) practices. ${ }^{18,19}$
The knowledge section included questions about the cause of the COVID-19, mode of transmission, common symptoms, complications, and the available treatment of the disease. The "attitudes" part included questions related to the seriousness of the disease and whether the student worries about suffering from or is at risk of COVID-19 infection, hence, disturbing the daily life. Moreover, some of the included questions explored the interest of students in knowing the methods of prevention, if the available information about COVID-19 was adequate and if the adoption of isolation measures and awareness could prevent or reduce the infection. The questions in the "practices" part were related to covering of the mouth and nose while sneezing, disposing of used tissues in the bin, and handwashing practices. Furthermore, this section inquired about the use of disinfectant and face mask, social distancing, contact with a person with COVID-19 and those with flu symptoms, touching or shaking hands, and seeking medical advice in case of any COVID-19 symptoms. Each item in the KAP sections marked correctly by the students based on the information provided by the Ministry of Health and Prevention (MOHAP) ${ }^{9}$ was given one point. The total scores of these items were then converted to percentages $(0-100 \%)$. The scores of $\leq 60 \%$ were classified as poor knowledge, negative attitude, or high-risk practices; the scores of $60.1-80 \%$ were moderate knowledge, moderate attitude, or moderate-risk practices; and the scores of $\geq 80.1 \%$ were good knowledge, positive attitude, or low-risk practices. ${ }^{18,19}$

The collected data were analyzed using Statistical Package for the Social Sciences software, version 25.0 (SPSS, Chicago, IL). Categorical variables were expressed as frequencies and percentages, and continuous variables were expressed as mean $\pm \mathrm{SD}$. Independent $t$-test was used to compare the means of the knowledge scores of HR and NHR students. Statistical significance levels were set at $P<0.05$. Chi-square test was used to explore the association between categorical variables. Sequential regression analysis was also carried out to explore the best predictors for the knowledge score.

Figure 1 shows the time line of the study from the time of the revision to online transformation, to ethical application, and to sending the email to the participants until data analysis, writeup, and submission of the manuscript.

\section{RESULTS}

The sample consists of 1,300 students from the UOS who were invited to participate in the study, and 1,012 students (19.4\% males; $80.6 \%$ females) completed the questionnaire (response rate $77.8 \%$ ).

As shown in Table 1, more than half (58\%) of the students' age ranged between 20 and 25 years. The majority of participants $(88.9 \%)$ were Arab students, and $93.9 \%$ were single. About $51 \%$ and $41 \%$ of the students were living in villa and apartment, respectively. The distribution of students in HR (College of Health Sciences, Medicine, Dentistry, and Pharmacy) and NHR (all other colleges) majors was $47.5 \%$ and $52.5 \%$, respectively.

Table 2 shows the knowledge of the students toward COVID-19. Almost all the students (99.3\%) knew about COVID-19, and their top three sources of information were Internet (any website unrelated to social messaging networks), social media (Facebook, Instagram, WhatsApp, and Snapchat) $(85.2 \%)$ and mass media $(56.5 \%)$, and official websites 


\begin{tabular}{|c|}
\hline $\begin{array}{l}\text { Survey questionnaire reviewed, pre- } \\
\text { tested and transferred to online format - } \\
\text { April } 2020\end{array}$ \\
\hline $\begin{array}{l}\text { Ethical approval applied for and received } \\
\text { on the } 4^{\text {th }} \text { May } 2020\end{array}$ \\
\hline $\begin{array}{c}\text { Online web-based survey emailed to } \\
\text { students via the registration department } \\
\text { on the } 4^{\text {th }} \text { May } 2020\end{array}$ \\
\hline $\begin{array}{l}\text { Data collection period from the } 4^{\text {th }} \text { May } \\
\text { to } 11^{\text {th }} \text { May } 2020\end{array}$ \\
\hline $\begin{array}{l}\text { Data analysis and write up completed } \\
\text { and the manuscript was submitted on the } \\
\qquad 14^{\text {th }} \text { July } 2020\end{array}$ \\
\hline
\end{tabular}

FIGURE 1. Time line of the study.

(WHO, CDC, MOHAP and other authorities in the UAE, UOS) (51\%). A considerable percentage of students $(46.5 \%)$ were not sure that the type of genetic materials in COVID-19 is RNA. However, $76.6 \%$ of the students were aware that COVID-19 infection is caused by a new member of the coronavirus. The majority of students (95.9\%) were aware of cases of COVID-19 in the UAE, and $91.6 \%$ indicated that the history of travel was important to identify the risk of transmission of COVID-19. Only $10.4 \%$ of students indicated that there is no need for intensive and emergency treatment for a person with COVID19. A large percentage of the students (91.8\%) linked severe COVID-19 to death because of respiratory failure, with HR students more likely to report mortality of less than $5.0 \%$ than NHR students (40.1\% versus $30.1 \%, P<0.001)$. Almost all the students (98.1\%) agreed that a person with COVID-19 should be immediately isolated, and more than three-fourths of the students $(79.5 \%)$ concurred that complete recovery is possible in a person with COVID-19. Interestingly, $80.8 \%$ of the students agreed that the only effective treatment for COVID19 is symptomatic.

More HR students identified the cause of COVID-19 was a virus than NHR students $(99.6 \%$ versus $91.6 \%, P<0.001)$, with HR students being aware that it was caused by a new member of coronavirus $(79.6 \%$ versus $73.8 \%, P=0.004)$. A larger number of HR students identified travel history as being an important risk factor (HR versus NHR: $96.7 \%$ versus $87 \%$, $P<0.001$ ). Approximately $69 \%$ of HR students indicated that the incubation period for COVID-19 is $\leq 14$ days versus $52.7 \%$
TABLE 1

Sociodemographic characteristics of the participants $(N=1,012)$

\begin{tabular}{llc}
\hline Variable & & $\%(\mathrm{~N})$ \\
\hline Age-groups (years) & & \\
& $18-19.9$ & $37.5(380)$ \\
\multirow{2}{*}{ Gender } & $20-25$ & $58.0(587)$ \\
& $>25$ & $4.4(45)$ \\
Nationality & Males & $19.4(196)$ \\
& Females & $80.6(816)$ \\
Marital status & Arab & $88.9(900)$ \\
& Non-Arab & $11.1(112)$ \\
Place of residency & Married & $93.9(950)$ \\
& Villa & $6.1(62)$ \\
& Apartment & $50.8(514)$ \\
Majors & University dormitories & $40.9(414)$ \\
& & $8.3(84)$ \\
& Health related & $47.5(481)$ \\
& Non-health related & $52.5(531)$ \\
\hline
\end{tabular}

of NHR students $(P<0.001)$. Health-related students also reported that people with COVID-19 must be immediately isolated (HR versus NHR: $99.6 \%$ versus $96.8 \%, P=0.004$ ), and antibiotics are an ineffective treatment as compared with NHR students. A larger percentage of HR students indicated that the only effective treatment for COVID-19 was symptomatic (HR versus NHR: $89 \%$ versus $73.4 \%, P<0.001$ ).

Calculation of the knowledge score revealed that the mean score in percentage was $72.3 \pm 10.62$. Health-related students had significantly higher scores than NHR students $(76 \%$ versus $69 \%, P<0.001)$.

Table 3 illustrates the attitude of the UOS students toward COVID-19. About $85 \%$ of the students believe that COVID-19 is dangerous ( $\mathrm{HR}$ versus NHR: students: $82.5 \%$ versus $87.6 \%, P=0.024)$, and three-fourths of the students $(76 \%)$ were worried about suffering from this infection. A large number of the students $(74.1 \%)$ felt they are not at risk for COVID-19, and close to $90 \%$ stated that the disease had disturbed their daily lives. The majority (89.3\%) were interested in obtaining more information about the methods of prevention of COVID-19, whereas only $61.6 \%$ considered that the available information is sufficient. Most students (91.4\%) thought that adopting isolation measures could prevent COVID-19, and $95.7 \%$ believed that awareness could reduce COVID-19 infection.

Calculation of the attitude score revealed that the mean score was $72 \% \pm 14.5 \%$, with no significant differences between HR and NHR majors.

Table 4 demonstrates the practices of UOS students toward prevention of COVID-19. Most students (95.5\%) cover their nose and mouth with elbow or tissue when coughing or sneezing, and $96.2 \%$ throw away the used tissue into the bin. The students wash their hands regularly when they come back home (92.3\%), after toilet (90\%), before eating (87.1\%), after touching doorknobs or elevator buttons (85.5\%), after touching personal items of someone who has a cough and/or cold (84\%), after shaking hands with others $(75.5 \%)$, and before touching eyes or nose (62\%). Almost all the students $(99.4 \%)$ used soap during handwashing, and about three- 
TABLE 2

Knowledge of the participants toward COVID-19

\begin{tabular}{|c|c|c|c|c|}
\hline & $\begin{array}{c}\text { All }(N=1,012) \\
\%(N)\end{array}$ & $\begin{array}{l}\text { Health-related majors } \\
\qquad(N=481), \%(N)\end{array}$ & $\begin{array}{c}\text { Non-health-related } \\
\text { majors }(N=531), \%(N)\end{array}$ & $P$-value \\
\hline \multicolumn{5}{|l|}{ Do you know what COVID-19 is? } \\
\hline Yes & $99.3(1,005)^{\star}$ & $99.4(478)$ & $99.2(527)$ & 0.8 \\
\hline No & $0.7(7)$ & $0.6(3)$ & $0.8(4)$ & \\
\hline \multicolumn{5}{|l|}{ What are your source(s) of COVID-19 information? } \\
\hline Internet and social media & $85.2(862)$ & $84.4(406)$ & $85.9(456)$ & 0.51 \\
\hline Mass media & $56.5(572)$ & 54.7 (263) & $58.2(309)$ & 0.26 \\
\hline Official websites and scientific articles & $51.0(516)$ & $63.0(303)$ & $40.1(213)$ & $<0.001$ \\
\hline Friends and families & $47.5(481)$ & $48.9(235)$ & $46.3(246)$ & 0.42 \\
\hline \multicolumn{5}{|l|}{ What is the cause of COVID-19 disease? } \\
\hline Virus & $95.6(967)^{\star}$ & $99.6(479)$ & $91.9(488)$ & $<0.001$ \\
\hline Bacteria & $1.1(11)$ & $0.0(0)$ & $2.1(11)$ & \\
\hline Not sure & $3.4(34)$ & $0.4(2)$ & $6.0(32)$ & \\
\hline \multicolumn{5}{|l|}{ What is the type of genetic material in COVID-19? } \\
\hline DNA & $20.0(202)$ & $24.5(118)$ & $15.8(84)$ & $<0.001$ \\
\hline RNA & $33.5(339)^{\star}$ & 45.5 (219) & $22.6(120)$ & \\
\hline Not sure & $46.5(471)$ & $29.9(144)$ & $61.6(327)$ & \\
\hline \multicolumn{5}{|l|}{ Is COVID-19 caused by a new member of coronavirus? } \\
\hline Yes & $76.6(775)^{\star}$ & $79.6(383)$ & $73.8(392)$ & 0.004 \\
\hline No & $15.7(159)$ & $15.6(75)$ & $15.8(84)$ & \\
\hline Not sure & $7.7(78)$ & $4.8(23)$ & $10.4(55)$ & \\
\hline \multicolumn{5}{|l|}{ Are there COVID-19 cases in the UAE? } \\
\hline Yes & $95.9(971)^{\star}$ & $97.7(470)$ & $94.4(501)$ & 0.025 \\
\hline No & $1.0(10)$ & $0.6(3)$ & $1.3(7)$ & \\
\hline Not sure & $3.1(31)$ & $1.7(8)$ & $4.3(23)$ & \\
\hline \multicolumn{5}{|l|}{$\begin{array}{l}\text { Should the history of travel to areas experiencing transmission of COVID-19 } \\
\text { be considered to identify persons at risk of having COVID-19? }\end{array}$} \\
\hline Yes & $91.6(927)^{\star}$ & $96.7(465)$ & $87.0(462)$ & $<0.001$ \\
\hline No & $2.2(22)$ & $0.8(4)$ & $3.4(18)$ & \\
\hline Not sure & $6.2(63)$ & $2.5(12)$ & $9.6(51)$ & \\
\hline \multicolumn{5}{|l|}{ Which of the following includes the mode(s) of COVID-19 transmission? } \\
\hline Coughing and sneezing & $94.7(958)^{\star}$ & $95.6(460)$ & $93.8(498)$ & 0.19 \\
\hline Kissing and shaking hands & $90.9(920)^{\star}$ & $90.6(436)$ & $91.1(484)$ & 0.78 \\
\hline Touching contaminated surfaces & $88.8(899)^{\star}$ & $88.8(427)$ & $88.9(472)$ & 0.95 \\
\hline Touching the nose or mouth & $87.6(887)^{\star}$ & $90.2(434)$ & $85.3(453)$ & 0.02 \\
\hline $\begin{array}{l}\text { Saliva and nasal drip from the sick person } \\
\text { with COVID-19 }\end{array}$ & $80.9(819)^{*}$ & $87.3(420)$ & $75.1(399)$ & $<0.001$ \\
\hline $\begin{array}{l}\text { The use of objects owned by a } \\
\text { COVID-19-infected person }\end{array}$ & $80.2(812)^{\star}$ & $85.2(410)$ & $75.7(402)$ & $<0.001$ \\
\hline Air & $36.1(366)$ & $37.2(179)$ & $35.2(187)$ & 0.50 \\
\hline Sexual route & $32.2(326)$ & $28.3(136)$ & $35.8(190)$ & 0.01 \\
\hline Consuming foods & $17.6(178)^{\star}$ & $16.6(80)$ & $18.5(98)$ & 0.44 \\
\hline \multicolumn{5}{|l|}{ What is the incubation period for COVID-19? } \\
\hline$\leq 14$ days & $60.5(612)^{\star}$ & $69.0(332)$ & $52.7(280)$ & $<0.001$ \\
\hline$>14$ days & $34.6(350)$ & $29.1(140)$ & $39.6(210)$ & \\
\hline Not sure & $4.9(50)$ & $1.9(9)$ & $7.7(41)$ & \\
\hline \multicolumn{5}{|l|}{ Which of the following include people at high-risk group? } \\
\hline Elderly & $93.9(950)^{\star}$ & $96.3(463)$ & $91.7(487)$ & 0.003 \\
\hline $\begin{array}{l}\text { Old people with comorbidity such as diabetes, } \\
\text { cancer, and other chronic diseases }\end{array}$ & $88.7(898)^{*}$ & $92.9(447)$ & $84.9(451)$ & $<0.001$ \\
\hline Children younger than 5 years & $50.0(506)$ & $49.3(237)$ & $50.7(269)$ & 0.66 \\
\hline Pregnant women & $42.8(433)^{\star}$ & $47.4(228)$ & $38.6(205)$ & 0.005 \\
\hline Adults & $19.8(200)$ & $16.8(81)$ & $22.4(119)$ & 0.03 \\
\hline \multicolumn{5}{|l|}{ What are the most common symptoms of the disease? } \\
\hline Fever & $94.4(955)^{\star}$ & $95.2(458)$ & $93.6(497)$ & 0.26 \\
\hline Difficulty of breathing & 91.7 (928) & $94.2(453)$ & $89.5(475)$ & 0.007 \\
\hline Dry cough & $90.0(911)^{\star}$ & $91.9(442)$ & $88.3(469)$ & 0.06 \\
\hline Sore throat & $75.3(762)$ & $75.5(363)$ & 75.1 (399) & 0.90 \\
\hline Headache & $71.1(720)$ & $71.3(343)$ & $71.0(377)$ & 0.91 \\
\hline Tiredness & $42.9(434)^{\star}$ & $45.3(218)$ & 40.7 (216) & 0.14 \\
\hline Runny nose & 39.1 (396) & $39.3(189)$ & $39.0(207)$ & 0.92 \\
\hline Diarrhea & $23.5(238)$ & 23.1 (111) & 23.9 (127) & 0.75 \\
\hline Vomiting & $16.0(162)$ & $15.8(76)$ & $16.2(86)$ & 0.86 \\
\hline Blurred vision & $8.8(89)$ & $6.4(31)$ & $10.9(58)$ & 0.01 \\
\hline Skin rash & $7.3(74)$ & $7.5(36)$ & $7.2(38)$ & 0.84 \\
\hline \multicolumn{5}{|l|}{ Should intensive and emergency treatment be given to diagnosed patients? } \\
\hline Yes & $84.7(857)$ & $79.6(383)$ & $89.3(474)$ & $<0.001$ \\
\hline No & $10.4(105)^{*}$ & $13.7(66)$ & $7.3(39)$ & \\
\hline Not sure & $4.9(50)$ & $6.7(32)$ & $3.4(18)$ & \\
\hline
\end{tabular}


TABLE 2

Continued

\begin{tabular}{|c|c|c|c|c|}
\hline & $\begin{array}{c}\text { All }(N=1,012) \\
\%(N)\end{array}$ & $\begin{array}{l}\text { Health-related majors } \\
(N=481), \%(N)\end{array}$ & $\begin{array}{c}\text { Non-health-related } \\
\text { majors }(N=531), \%(N)\end{array}$ & $P$-value \\
\hline \multicolumn{5}{|l|}{ Which of the following includes complications of COVID-19 infection? } \\
\hline Bronchitis & $51.5(521)$ & 51.7 (249) & $51.2(272)$ & 0.86 \\
\hline Sepsis & $46.0(466)^{\star}$ & $43.0(207)$ & $48.8(259)$ & 0.07 \\
\hline Pneumonia & $41.6(421)^{\star}$ & $50.7(244)$ & $33.3(177)$ & $<0.001$ \\
\hline Multi-organ failure & $23.3(236)^{\star}$ & 26.8 (129) & $20.2(107)$ & 0.01 \\
\hline Hyperglycemia (high blood sugar) & $4.3(44)$ & $6.7(32)$ & $2.3(12)$ & 0.001 \\
\hline \multicolumn{5}{|l|}{$\begin{array}{l}\text { If severe COVID-19 infection leads to death, is it usually caused by } \\
\text { respiratory failure? }\end{array}$} \\
\hline Yes & $91.8(929)^{\star}$ & $95.2(458)$ & $88.7(471)$ & \multirow[t]{3}{*}{$<0.001$} \\
\hline No & $1.7(17)$ & $2.3(11)$ & $1.1(6)$ & \\
\hline Not sure & $6.5(66)$ & $2.5(12)$ & $10.2(54)$ & \\
\hline \multicolumn{5}{|l|}{$\begin{array}{l}\text { What is the approximate mortality rate in average patient infected with } \\
\text { COVID-19? (\%) }\end{array}$} \\
\hline$<5$ & $34.9(353)^{\star}$ & $40.1(193)$ & $30.1(160)$ & \multirow[t]{4}{*}{$<0.001$} \\
\hline $5-15$ & $33.8(342)$ & $34.1(164)$ & 33.5 (178) & \\
\hline $15-30$ & $17.4(176)$ & $16.0(77)$ & $18.6(99)$ & \\
\hline$>30$ & $13.9(141)$ & $9.8(47)$ & $17.7(94)$ & \\
\hline \multicolumn{5}{|l|}{ Should COVID-19 cases be immediately isolated? } \\
\hline Yes & $98.1(993)^{\star}$ & $99.6(479)$ & $96.8(514)$ & \multirow[t]{3}{*}{0.004} \\
\hline No & $0.4(4)$ & $0.0(0)$ & $0.8(4)$ & \\
\hline Not sure & $1.5(15)$ & $0.4(2)$ & $2.4(13)$ & \\
\hline \multicolumn{5}{|l|}{ Could COVID-19 affect humans more than once in their lives? } \\
\hline Yes & $57.8(585)^{\star}$ & $59.3(285)$ & $56.5(300)$ & \multirow[t]{3}{*}{0.17} \\
\hline No & $17.8(180)$ & $18.9(91)$ & $16.8(89)$ & \\
\hline Not sure & $24.4(247)$ & $21.8(105)$ & 26.7 (142) & \\
\hline \multicolumn{5}{|l|}{ Are antibiotics an effective medication in the treatment of COVID-19? } \\
\hline Yes & $13.4(136)$ & $10.2(49)$ & $16.4(87)$ & \multirow[t]{3}{*}{$<0.001$} \\
\hline No & $60.0(607)^{\star}$ & $72.8(350)$ & $48.4(257)$ & \\
\hline Not sure & $26.6(269)$ & $17.0(82)$ & $35.2(187)$ & \\
\hline \multicolumn{5}{|c|}{ Is the current effective treatment for COVID-19 only by reducing symptoms? } \\
\hline Yes & $80.8(818)^{\star}$ & $89.0(428)$ & $73.4(390)$ & \multirow[t]{3}{*}{$<0.001$} \\
\hline No & $8.1(82)$ & $6.0(29)$ & $10.0(53)$ & \\
\hline Not sure & $11.1(112)$ & $5.0(24)$ & $16.6(88)$ & \\
\hline \multicolumn{5}{|l|}{ Could COVID-19-infected people recover completely? } \\
\hline Yes & $79.5(805)^{\star}$ & $78.4(377)$ & $80.6(428)$ & \multirow[t]{3}{*}{0.06} \\
\hline No & $10.3(104)$ & $12.5(60)$ & $8.3(44)$ & \\
\hline Not sure & $10.2(103)$ & $9.1(44)$ & $11.1(59)$ & \\
\hline \multicolumn{5}{|l|}{ Is there a vaccine for COVID-19? } \\
\hline Yes & $10.4(105)$ & $7.7(37)$ & $12.8(68)$ & \multirow[t]{3}{*}{$<0.001$} \\
\hline No & $66.9(677)^{*}$ & 77.5 (373) & $57.3(304)$ & \\
\hline Not sure & $22.7(230)$ & $14.8(71)$ & 29.9 (159) & \\
\hline Knowledge score $\dagger$ (total is $31 ; 0=0 \%$ and $31=100 \%$ ) & $72.3 \pm 10.62$ & $76 \pm 8.45$ & $69 \pm 11.31$ & $<0.001$ \\
\hline
\end{tabular}

$\dagger$ Using independent t-test to compare the knowledge score of the health-related and non-health-related students. As multiple responses were allowed, the total number of responses is greater than the number of surveyed participants, and percent of cases is displayed.

quarters wash hands before sleeping, with $20.7 \%$ washing their hands for greater than 20 seconds (HR versus NHR: $21.2 \%$ versus $20.2 \%, P=0.015)$. The majority (86.2\%) used disinfectant, disposable wipes, or hand gel for sanitization. About $90 \%$ of the students used face masks (HR versus NHR: $88.4 \%$ versus $92.3 \%, P=0.034$ ), with $71.3 \%$ using their mask in crowded areas, $46.8 \%$ always wearing masks, and $41.6 \%$ using masks only during fever, cough, or runny nose. The majority of the students $(98.3 \%)$ avoid going to crowded places (HR versus NHR: $99.4 \%$ versus $97.4 \%, P=0.013$ ), and 95.4\% practice social distancing (HR versus NHR: $97.7 \%$ versus $93.2 \%, P=0.001)$. Almost all the students $(99.5 \%)$ avoided contact with a person with COVID-19, with $94.2 \%$ avoiding touching or shaking hands and $90.4 \%$ avoiding contact with other people if they have flu-like symptoms. Nearly all $(96 \%)$ the students concurred that they will seek medical advice if they experience any symptoms of COVID-19 infection.

Calculation of the practice revealed that the mean score was $85.6 \% \pm 11.8 \%$, with no significant difference in score between HR and NHR students.
Table 5 depicts the sequential regression analysis using the knowledge score as a dependent variable and gender, nationality, or study majors as independent variables. It shows that model 3 has the largest and significant $R$ square change (0.108, $P<0.001)$, and the two significantly associated variables were the gender and study majors $(B=-0.51, P=0.04$, 95\% Cl: -1.01 to -0.01 and $B=-2.23, P<0.001$. 95\% Cl: -2.62 to -1.83 , respectively). The results show that males and HR majors had higher knowledge score; however, study major was the best predictor for the knowledge score.

\section{DISCUSSION}

Following the COVID-19 pandemic, as part of the Ministry of Education and MOHAP guidelines for all universities and students in the UAE, all teaching (including theory, laboratory, and clinical courses) were changed from $100 \%$ face-to-face to $100 \%$ online delivery. Furthermore, guidelines were provided to all university students, faculty, and staff in mid-March, for enhancing knowledge and practices to prevent COVID-19 
TABLE 3

Attitude of the participants toward COVID-19

\begin{tabular}{|c|c|c|c|c|}
\hline & $\begin{array}{c}\text { All }(N=1,012) \\
\%(N)\end{array}$ & $\begin{array}{l}\text { Health-related majors } \\
\quad(N=481), \%(N)\end{array}$ & $\begin{array}{l}\text { Non-health-related majors } \\
\quad(N=531), \%(N)\end{array}$ & $P$-value \\
\hline \multicolumn{5}{|l|}{ Do you think that COVID-19 is a dangerous disease? } \\
\hline Yes & $85.2(862)^{\star}$ & $82.5(397)$ & $87.6(465)$ & \multirow[t]{2}{*}{0.024} \\
\hline No & $14.8(150)$ & $17.5(84)$ & $12.5(66)$ & \\
\hline \multicolumn{5}{|l|}{ Do you worry about suffering from COVID-19? } \\
\hline Yes & $76.2(771)$ & $74.2(357)$ & $78.0(414)$ & \multirow[t]{2}{*}{0.16} \\
\hline No & $23.8(241)$ & $25.8(124)$ & $22.0(117)$ & \\
\hline \multicolumn{5}{|l|}{ Are you at risk of getting COVID-19 infection? } \\
\hline Yes & $25.9(262)^{\star}$ & $25.2(121)$ & $26.6(141)$ & \multirow[t]{2}{*}{0.61} \\
\hline No & $74.1(750)$ & $74.8(360)$ & $73.4(390)$ & \\
\hline \multicolumn{5}{|l|}{ Has your daily life been disturbed by COVID-19? } \\
\hline Yes & $89.2(903)$ & $88.8(427)$ & $89.6(476)$ & \multirow[t]{2}{*}{0.65} \\
\hline No & $10.8(109)$ & $11.2(54)$ & $10.4(55)$ & \\
\hline \multicolumn{5}{|c|}{ Are you interested in knowing the methods of prevention of COVID-19? } \\
\hline Yes & $89.3(904)^{\star}$ & $90.2(434)$ & $88.5(470)$ & \multirow[t]{2}{*}{0.37} \\
\hline No & $10.7(108)$ & $9.8(47)$ & $11.5(61)$ & \\
\hline \multicolumn{5}{|c|}{ How would you describe the available information about COVID-19? } \\
\hline Sufficient & $61.6(623)$ & $61.1(294)$ & $62.0(329)$ & \multirow[t]{2}{*}{0.78} \\
\hline Insufficient & $38.4(389)^{\star}$ & $38.9(187)$ & $38.0(202)$ & \\
\hline \multicolumn{5}{|c|}{$\begin{array}{l}\text { Could the novel COVID-19 disease be prevented by adopting the } \\
\text { isolation measures? }\end{array}$} \\
\hline Yes & $91.4(925)^{\star}$ & $91.1(438)$ & $91.7(487)$ & \multirow[t]{2}{*}{0.71} \\
\hline No & $8.6(87)$ & $8.9(43)$ & $8.3(44)$ & \\
\hline \multicolumn{5}{|l|}{ Could the COVID-19 be reduced by awareness? } \\
\hline Yes & $95.7(968)^{*}$ & $96.9(466)$ & $94.5(502)$ & \multirow[t]{2}{*}{0.07} \\
\hline No & $4.3(44)$ & $3.1(15)$ & $5.5(29)$ & \\
\hline Attitudes score (total is $6 ; 0=0 \%$ and $6=100 \%$ ) & $72 \pm 14.5$ & $71.72 \pm 13.85$ & $72.19 \pm 15.11$ & 0.29 \\
\hline
\end{tabular}

infection in the community. Students form a very important and influential population group both for their peers and families. Hence, their perspective is crucial to evaluate current KAP toward COVID-19 to provide recommendations for improvements in these areas. This study was conducted to evaluate and compare the KAP of HR and NHR UOS students toward COVID-19. Of the 1,012 students who completed the KAP questionnaire, most were female Arab students. Student responses from HR and NHR majors were almost equal. Although the students from all majors had acceptable knowledge, positive attitudes, and adequate practices, there was a scope for improvement in certain key areas that will be highlighted in the following text.

Regarding the knowledge of COVID-19, more than $80 \%$ of students relied on the Internet and social media as the main source of information as opposed to more traditional sources such as newspapers, television channels, radio, or scientific websites. This could be attributed to the fact that the student population is young and have their mobile devices with Internet availability almost all the time. ${ }^{20}$ Although the UOS sent announcements via email, on their Facebook, Instagram, and Linked-in pages ${ }^{14-16}$ for the university, the number of students accessing official websites is limited. Most students who relied on social media may have become victims of misinformation and fabricated knowledge from unreliable sources. The university needs to concentrate efforts to direct students to credible social media platform pages. Most of the students attributed "a virus" as the cause of COVID-19 disease. However, almost two-thirds of students from all majors were not able to identify RNA as the type of genetic material of the virus. Similar findings were reported by another study conducted in the Jordanian students. ${ }^{18}$ More HR students were able to identify the genetic material type with HR students more likely to report mortality of less than $5 \%$ than NHR students $(40.1 \%$ versus $30.1 \%, P<0.001)$ possibly because their curriculum includes information regarding viruses, or they are more interested in learning health-related information.

Most of the students indicated that history of travel was important to identify the risk of COVID-19 transmission; however, more HR students indicated this. A significant number of the students reported good awareness about the modes of transmission, although a little over $50 \%$ were aware of the incubation period for COVID-19. This is very similar to that found in Pakistani University community. ${ }^{21}$ Recent evidence indicates that aerosols related to certain medical procedures carried out on people with COVID-19 could be a potential source of infection if inhaled by those who are not wearing personal protective equipment. Furthermore, aerosol transmission linked to infection in closed spaces can also be a source of infection ${ }^{22}$; however, air was significantly identified as a mode of transmission in the current study. More awareness needs to be raised, and further research needs to be conducted in this area.

More than $80 \%$ of all the students were able to identify elderly and those with comorbidities as a high-risk group for COVID-19; however, only approximately $40 \%$ identified that pregnant women are at high risk. Half of the students identified children younger than 5 years to be at high risk, which is contrary to that reported by the CDC and WHO. 9,11,18,23 This could be attributed to the movement restrictions applied to children for malls and public places. ${ }^{12}$ It is recommended that public programs by the government focus on enhancing awareness of the high-risk groups for COVID-19.

Almost all the students were aware of common symptoms such as fever and dry cough as identified by the MOHAP'; however, less than half of the students were aware of tiredness as being an additional common symptom for COVID-19. It has been extensively reported that more than $80 \%$ of people with 
TABLE 4

Practices of the participants toward COVID-19

\begin{tabular}{|c|c|c|c|c|}
\hline & $\begin{array}{c}\text { All }(N=1,012) \\
\%(N)\end{array}$ & $\begin{array}{l}\text { Health-related majors } \\
(N=481), \%(N)\end{array}$ & $\begin{array}{l}\text { Non-health-related majors } \\
\qquad(N=531), \%(N)\end{array}$ & $P$-value \\
\hline \multicolumn{5}{|l|}{$\begin{array}{l}\text { Do you cover your nose and mouth with elbow or tissue when coughing } \\
\text { and sneezing? }\end{array}$} \\
\hline Yes & $95.5(966)^{*}$ & $96.7(465)$ & $94.4(501)$ & \multirow[t]{2}{*}{0.07} \\
\hline No & $4.5(46)$ & $3.3(16)$ & $5.6(30)$ & \\
\hline \multicolumn{5}{|l|}{ Do you throw away the used tissue into the bin? } \\
\hline Yes & $96.2(974)^{\star}$ & $97.1(467)$ & $95.5(507)$ & \multirow{2}{*}{0.18} \\
\hline No & $3.8(38)$ & $2.9(14)$ & $4.5(24)$ & \\
\hline \multicolumn{5}{|l|}{ When do you wash your hands? } \\
\hline When you come back home & $92.3(934)^{\star}$ & $92.9(447)$ & $91.7(487)$ & 0.47 \\
\hline After toilet & $90.0(911)^{\star}$ & $94.6(455)$ & $85.9(456)$ & $<0.001$ \\
\hline After touching doorknobs or elevator buttons & $85.5(865)^{\star}$ & $85.2(410)$ & 85.7 (455) & 0.84 \\
\hline Before eating & $87.1(881)^{\star}$ & $89.4(430)$ & $84.9(451)$ & 0.03 \\
\hline $\begin{array}{l}\text { After touching the personal items of someone } \\
\text { who has a cough and/or cold }\end{array}$ & $84.0(850)^{*}$ & $83.6(402)$ & $84.4(448)$ & 0.73 \\
\hline After shaking hands with others & $75.5(764)^{\star}$ & $73.4(353)$ & $77.4(411)$ & 0.14 \\
\hline Before touching eyes or nose & $62.0(627)^{*}$ & $61.5(296)$ & $62.3(331)$ & 0.79 \\
\hline \multicolumn{5}{|l|}{ Do you use soap in hand washing? } \\
\hline Yes & $99.4(1,006)^{\star}$ & $99.2(477)$ & $99.6(529)$ & \multirow[t]{2}{*}{0.35} \\
\hline No & $0.6(6)$ & $0.8(4)$ & $0.4(2)$ & \\
\hline \multicolumn{5}{|l|}{ Do you wash your hands before sleeping? } \\
\hline Yes & $74.2(751)$ & $72.8(350)$ & $75.5(401)$ & \multirow[t]{2}{*}{0.32} \\
\hline No & $25.8(261)^{\star}$ & $27.2(131)$ & $24.5(130)$ & \\
\hline \multicolumn{5}{|l|}{ How much time do you spend washing your hands? (seconds) } \\
\hline Less than 10 & $15.5(157)$ & $12.1(58)$ & $18.6(99)$ & \multirow[t]{3}{*}{0.015} \\
\hline $10-20$ & $63.8(646)$ & $66.7(321)$ & $61.2(325)$ & \\
\hline More than 20 & $20.7(209)^{\star}$ & $21.2(102)$ & $20.2(107)$ & \\
\hline \multicolumn{5}{|l|}{$\begin{array}{l}\text { Do you use disinfectant, disposable wipes or hand gel to wash } \\
\text { your hands? }\end{array}$} \\
\hline Yes & $86.2(872)^{\star}$ & $86.1(414)$ & $86.3(458)$ & \multirow[t]{2}{*}{0.93} \\
\hline No & $13.8(140)$ & $13.9(67)$ & $13.7(73)$ & \\
\hline \multicolumn{5}{|l|}{ Do you use a face mask? } \\
\hline Yes & $90.4(915)^{\star}$ & $88.4(425)$ & $92.3(490)$ & \multirow[t]{2}{*}{0.034} \\
\hline No & $9.6(97)$ & $11.6(56)$ & $7.7(41)$ & \\
\hline \multicolumn{5}{|l|}{ When do you use a face mask? } \\
\hline At crowded areas & $71.3(722)$ & $74.2(357)$ & $68.7(365)$ & \multirow{3}{*}{$\begin{array}{c}0.05 \\
<0.001 \\
0.02\end{array}$} \\
\hline Always wearing face mask & $46.8(474)$ & 39.7 (191) & $53.3(283)$ & \\
\hline When having fever, cough, or runny nose & $41.6(421)$ & $45.3(218)$ & $38.2(203)$ & \\
\hline \multicolumn{5}{|l|}{ Do you avoid going to crowded places? } \\
\hline Yes & $98.3(995)^{*}$ & $99.4(478)$ & $97.4(517)$ & \multirow[t]{2}{*}{0.013} \\
\hline No & $1.7(17)$ & $0.6(3)$ & $2.6(14)$ & \\
\hline \multicolumn{5}{|l|}{ Do you practice social distancing? } \\
\hline Yes & $95.4(965)^{\star}$ & $97.7(470)$ & $93.2(495)$ & 0.001 \\
\hline No & $4.6(47)$ & $2.3(11)$ & $6.8(36)$ & \\
\hline Do you avoid contact with COVID-19-infected case? & & & & \\
\hline Yes & $99.5(1,007)^{\star}$ & $99.8(480)$ & $99.2(527)$ & 0.21 \\
\hline No & $0.5(5)$ & $0.2(1)$ & $0.8(4)$ & \\
\hline Do you avoid touching or shaking hands? & & & & \\
\hline Yes & $94.2(953)^{\star}$ & $95.2(458)$ & $93.2(495)$ & 0.17 \\
\hline No & $5.8(59)$ & $4.8(23)$ & $6.8(36)$ & \\
\hline If you have flu symptoms, do you avoid contact with other people? & & & & \\
\hline Yes & $90.4(915)^{\star}$ & $91.5(440)$ & $89.5(475)$ & 0.27 \\
\hline No & $9.6(97)$ & $8.5(41)$ & $10.5(56)$ & \\
\hline $\begin{array}{l}\text { Would you seek medical advice if you experience any symptoms of } \\
\text { COVID-19 disease? }\end{array}$ & & & & \\
\hline Yes & $96.0(972)^{*}$ & $95.4(459)$ & $96.6(513)$ & 0.33 \\
\hline No & $4.0(40)$ & $4.6(22)$ & $3.4(18)$ & \\
\hline Practices score (total is $20 ; 0=0 \%$ and $20=100 \%$ ) & $85.6 \pm 11.8$ & $86.04 \pm 11.37$ & $85.25 \pm 12.21$ & 0.62 \\
\hline
\end{tabular}

COVID-19 have mild symptoms and recover without the need for intensive care. ${ }^{23}$ Nevertheless, almost $85 \%$ of the students reported a need for intensive and emergency treatment for all persons with COVID-19, which is another area that students need further awareness about.

Complications of COVID-19 focus on acute respiratory failure, pneumonia, acute respiratory distress syndrome, acute liver injury, acute cardiac injury, secondary infection, acute kidney injury, septic shock, and disseminated intravascular coagulation. ${ }^{24}$ About half the students were aware of the most common complications associated with COVID-19. This is lower than that reported by a study in Jordan with university students. In our study, $46 \%$ of the students reported sepsis as being a complication as opposed to a Jordanian study which reported only $5 \%$ of students identifying sepsis as a complication. ${ }^{18}$ Only one-fourth of our students identified that multi-organ failure is a 
TABLE 5

Sequential regression analysis using knowledge score as a dependent variable

\begin{tabular}{|c|c|c|c|c|c|c|c|c|c|c|c|c|}
\hline & \multicolumn{4}{|c|}{ Model 1} & \multicolumn{4}{|c|}{ Model 2} & \multicolumn{4}{|c|}{ Model 3} \\
\hline & \multicolumn{4}{|c|}{$\left(R^{2}=0.000, R^{2}\right.$ change $\left.=0.000\right)$} & \multicolumn{4}{|c|}{$\left(R^{2}=0.001, R^{2}\right.$ change $\left.=0.001\right)$} & \multicolumn{4}{|c|}{$\left(R^{2}=0.109, R^{2} \text { change }=0.108\right)^{\star}$} \\
\hline & \multirow[b]{2}{*}{$B$} & \multirow[b]{2}{*}{$P$-value } & \multicolumn{2}{|c|}{$95 \% \mathrm{Cl}$} & \multirow[b]{2}{*}{$B$} & \multirow[b]{2}{*}{$P$-value } & \multicolumn{2}{|c|}{$95 \% \mathrm{Cl}$} & \multirow[b]{2}{*}{$B$} & \multirow[b]{2}{*}{$P$-value } & \multicolumn{2}{|c|}{$95 \% \mathrm{Cl}$} \\
\hline & & & Lower & Upper & & & Lower & Upper & & & Lower & Upper \\
\hline Gender & 0.17 & 0.52 & -0.34 & 0.68 & 0.168 & 0.52 & -0.034 & 0.68 & -0.51 & 0.04 & -1.01 & -0.01 \\
\hline Nationality & - & - & - & - & 0.30 & 0.36 & -0.35 & 0.95 & 0.13 & 0.67 & -0.48 & 0.74 \\
\hline Majors & - & - & - & - & - & - & - & - & -2.23 & $<0.001$ & -2.62 & -1.83 \\
\hline
\end{tabular}

complication of COVID-19. This might be attributed to the fact that multi-organ failure is seen only in very severe COVID-19 cases, which constitute only $4 \%$ of infected people. ${ }^{23,25}$

It is well established that respiratory-related complications can result in a high mortality rate among COVID-19-infected patients, and the bulk of students in our study were able to relate severe COVID-19 to death because of respiratory failure, similar to the findings from Jordan ${ }^{18}$

Almost all the students demonstrated knowledge regarding immediate isolation of a person with COVID-19; however, only a little over half knew that COVID-19 could affect humans more than once in their lifetime. This is an important area to raise awareness as it might result in students not following social distancing, or more appropriately referred to as physical distancing, ${ }^{21}$ and other preventive measures once they have recovered from COVID-19.

Three-fourths of HR students reported that antibiotics are ineffective in treating COVID-19 as opposed to less than half of NHR students. This highlights that the differences in student majors may greatly impact health-related knowledge, and that awareness should be focused on those not in the healthcare sector.

About four-fifths of the students knew that complete recovery is possible, and till the time of writing this article, there is no available vaccine for COVID-19 or established effective treatment, and the primary management is symptomatic. ${ }^{26}$ However, more HR students were aware of the above information as opposed to approximately half of the NHR students. This again highlights the importance of awareness to be focused on the NHR sector.

Our students demonstrated moderate knowledge (72\%) comparable to medical students from Jordan, ${ }^{27}$ and greater than that reported by Saudi $^{28}$ and Pakistani students. ${ }^{21}$ However, our students reported lower knowledge than other majors' students from Jordan ${ }^{18}$ and Iranian public. ${ }^{29}$ Furthermore, sequential regression indicated that gender and study major are significantly associated with the knowledge score, with the latter being the best predictor as expected. Despite providing adequate information on the UOS website, media channels, and other sources, this study highlights the need to provide further knowledge awareness related to COVID-19 particularly in NHR majors.

Exploring the attitudes of the UOS students revealed that a large number believed that COVID-19 was dangerous, and about three-quarters were worried about suffering from the infection. This finding is very similar to the one in Pakistani students. ${ }^{21}$ Interestingly, the same percentage of students (three-quarters) believed that they were not at risk for getting COVID-19, which could be attributed to the study being conducted during the UAE lockdown and Ramadan (a periodic month of fasting every year for the Muslim community), both of which limited students' outings and subsequent contact with others.

Most of them were interested in obtaining more information about prevention of COVID-19, and only more than $50 \%$ felt that they had sufficient information. This gap needs to be bridged so that attitudes and practices can be improved.

Regarding the attitude score (72\%), our students demonstrated moderate positive attitudes toward COVID-19; however, these are lower than the percentage score among Jordanian students, ${ }^{19}$ suggesting the need to raise awareness in this important area.

Based on the CDC recommendations ${ }^{30}$ for using cloth masks in public places, almost all the students follow these practices when visiting public places. Furthermore, they also make sure to cover their nose and mouth while sneezing, and dispose of tissues appropriately. Regarding handwashing, students do wash it regularly after coming home, or using the washroom, but almost $60 \%$ do wash their hands regularly before touching the eyes or nose, which is a preventative recommendation. ${ }^{30}$ Furthermore, the recommendation to wash hands for more than 20 seconds $^{31}$ is only adhered by one-fifth of the students. The majority use disinfectant, disposable wipes, or hand gel for sanitization. This highlights areas where practices may be improved.

Most of the students avoid going to crowded places and practice social distancing. All students avoid contact with a person with COVID-19, including avoiding touching or shaking hands and avoiding contact with other people if they have flu-like symptoms. All the students concurred that they would seek medical advice if they experience any symptoms of COVID-19 infection. The students demonstrated a practice score of $85 \%$ reflecting low-risk practices of the students to prevent spread or risk of COVID-19 infection. This is similar to the finding in Jordanian students ${ }^{19}$; however, this is different as compared with other studies reporting unsatisfactory practices. ${ }^{21}$ This may be due to the fact that the population is young students who are up to date with the information.

In conclusion, large-scale pandemics, as we are apparently experiencing, test the integrity of awareness campaigns conducted regularly, especially on online platforms in a socially active population like university students. In our study, all students demonstrated adequate knowledge as evident by their knowledge scores. Furthermore, it is fulfilling to discover that the students also possess good attitudes and low-risk practices toward prevention of COVID-19. However, it is apparent that HR students fared 
better in all categories as than NHR students, especially in the knowledge domain. Unnecessary emergency and intensive treatment for every person with COVID-19, identification of the high-risk groups, particularly pregnant women, and the possibility of recurrence of COVID-19 infection highlighted three areas of focus for awareness campaigns for the UOS students, particularly those in NHR majors. The findings of this study reflect the importance for institutions like universities to develop appropriate educational programs and provide protective health measures for their faculty, staff, and students, especially considering the possibility of physical reopening in the spring semester. These might possibly include posters, seminars, information via social channels on good respiratory etiquette, handwashing practices, and physical distancing to enhance safer lifestyles and prevent COVID-19 transmission.

Received July 14, 2020. Accepted for publication November 10, 2020.

Published online November 23, 2020.

Acknowledgments: We would like to express our gratitude to the participants and the registration department for their help in disseminating the survey via university channels. Publication charges for this article were waived due to the ongoing pandemic of COVID-19.

Authors' addresses: Hayder Hasan, Department of Clinical Nutrition and Dietetics, College of Health Sciences, University of Sharjah, Sharjah, United Arab Emirates, and Research Institute of Medical and Health Sciences, University of Sharjah, Sharjah, United Arab Emirates, E-mail: haidarah@sharjah.ac.ae. Veena Raigangar, Department of Physiotherapy, College of Health Sciences, University of Sharjah, Sharjah, United Arab Emirates, and Research Institute of Medical and Health Sciences, University of Sharjah, Sharjah, United Arab Emirates, E-mail: veena@sharjah.ac.ae. Tareq Osaili, Department of Clinical Nutrition and Dietetics, College of Health Sciences, University of Sharjah, Sharjah, United Arab Emirates, Research Institute of Medical and Health Sciences, University of Sharjah, Sharjah, United Arab Emirates, and Department of Nutrition and Food Technology, Faculty of Agriculture, Jordan University of Science and Technology, Irbid, Jordan. E-mail: tosaili@sharjah.ac.ae. Noorieh E. Neinavaei, Department of Physiotherapy, College of Health Sciences, University of Sharjah, Sharjah, United Arab Emirates, E-mail: u14120309@ sharjah.ac.ae. Amin N. Olaimat, Department of Clinical Nutrition and Dietetics, Faculty of Applied Medical Sciences, The Hashemite University, Zarqa, Jordan, E-mail: aminolaimat@hu.edu.jo. Iman Aolymat, Department of Basic Medical Sciences, Faculty of Medicine, The Hashemite University, Zarqa, Jordan, E-mail: emanolaimat3@ gmail.com.

This is an open-access article distributed under the terms of the Creative Commons Attribution (CC-BY) License, which permits unrestricted use, distribution, and reproduction in any medium, provided the original author and source are credited.

\section{REFERENCES}

1. World Health Organization, 2020. There Is a Current Outbreak of Coronavirus (COVID-19) Disease Find Out More. Geneva, Switzerland: WHO. Available at: https://www.who.int/healthtopics/coronavirus\#tab=tab_1. Accessed June 16, 2020.

2. Lee $\mathrm{N}$ et al., 2003. A major outbreak of severe acute respiratory syndrome in Hong Kong. N Engl J Med 348: 1986-1994.

3. CDC, 2020. Middle East Respiratory Syndrome (MERS) | CDC. Available at: https://www.cdc.gov/coronavirus/mers/index. html. Accessed June 20, 2020.

4. XuX, Chen P, Wang J, Feng J, Zhou H, Li X, Zhong W, Hao P, 2020. Evolution of the novel coronavirus from the ongoing Wuhan outbreak and modeling of its spike protein for risk of human transmission. Sci China Life Sci Sci 63: 457-460.

5. World Health Organization, 2020. Coronavirus Disease 2019. Geneva, Switzerland: WHO. Available at: https://www.who.int/ emergencies/diseases/novel-coronavirus-2019. Accessed June 20,2020

6. World Health Organization, 2020 WHO Coronavirus Disease (COVID-19) Dashboard. Geneva, Switzerland: WHO. Available at: https://covid19.who.int/. Accessed June 20, 2020.

7. The National Newspaper, 2020. Coronavirus: UAE Records First Case. Available at: https://www.thenational.ae/uae/health/ coronavirus-uae-records-first-case-1.971253. Accessed June 20, 2020.

8. Worldometer, 2020. United Arab Emirates Coronavirus: 44,145 Cases and 300 Deaths. Available at: https://www.worldometers. info/coronavirus/country/united-arab-emirates/. Accessed September 16, 2020.

9. MOHAP, 2020. Novel Coronavirus (COVID-19) - Ministry of Health and Prevention - UAE. Available at: https://www.mohap.gov.ae/ en/AwarenessCenter/Pages/COVID-19.aspx. Accessed June 20, 2020.

10. Forbes, 2020. Dubai Enters 24-Hour Lockdown as Travel Restrictions Extended in UAE. Available at: https://www.forbes.com/ sites/jamesasquith/2020/04/05/dubai-enters-24-hour-lockdownas-travel-restrictions-extended-in-uae/\#7e1b9a8d4f31. Accessed June 20, 2020.

11. CDC, 2020. Coronavirus Disease $2019 \mid$ CDC. Available at: https:// www.cdc.gov/coronavirus/2019-ncov/symptoms-testing/ symptoms.html. Accessed June 20, 2020.

12. Gulf News, 2020. Dubai: Malls Partially Reopen with COVID-19 Precautions in Place | Uae - Gulf News. Available at: https:// gulfnews.com/uae/dubai-malls-partially-reopen-with-covid-19precautions-in-place-1.1587956797103. Accessed June 20, 2020.

13. UAE Government, 2020. Distance Learning in Times of COVID19 - the Official Portal of the UAE Government. Available at: https://u.ae/en/information-and-services/education/distancelearning-in-times-of-covid-19. Accessed September 10, 2020.

14. University of Sharjah, 2020. Available at: https://www.sharjah. ac.ae/en/Pages/default.aspx. Accessed June 20, 2020.

15. University of Sharjah, 2020. Overview | Linkedln. Available at: https://www.linkedin.com/school/university-of-sharjah/. Accessed June 20, 2020.

16. University of Sharjah, 2020. Facebook, 27-31. American Journal of Tropical Medicine and Hygiene. Available at: https://www. facebook.com/usharjah/. Accessed June 20, 2020.

17. Lemeshow L, Hosmer DW, Klar J, Lawanga SK, 1990. Adequacy of Sample Size in Health Studies. Geneva, Switzerland: World Health Organization. Available at: https://apps.who.int/iris/ bitstream/handle/10665/41607/0471925179_eng.pdf? sequence $=1$.

18. Olaimat AN, Aolymat I, Shahbaz HM, Holley RA, 2020. Knowledge and information sources about COVID-19 among university students in Jordan: a cross-sectional study. Front Public Health 8: 254.

19. Olaimat AN, Aolymat I, Elsahoryi N, Shahbaz HM, Holley RA, 2020. Attitudes, anxiety, and behavioral practices regarding COVID-19 among university students in Jordan: a cross-sectional study. Am J Trop Med Hyg 103: 1177-1183.

20. Vorderer P, Krömer N, Schneider FM, 2016. Permanently online permanently connected: explorations into university students' use of social media and mobile smart devices. Comput Hum Behav 63: 694-703.

21. Salman M, Mustafa ZU, Asif N, Haider ZA, Hussain K, Shehzadi N, Mehmood Khan T, Saleem Z, 2020. Knowledge, attitude and preventive practices related to COVID-19: a cross- sectional study in two Pakistani university populations. Drugs Ther Perspect 9: 1-7.

22. World Health Organization, 2020. Q\&A: How is COVID-19 Transmitted? Geneva, Switzerland: WHO. Available at: https:// www.who.int/emergencies/diseases/novel-coronavirus-2019/ question-and-answers-hub/q-a-detail/q-a-how-is-covid-19transmitted?gclid=CjwKCAjwtNf6BRAwEiwAkt6UQtGOLYKf P29sauzG5QkHvAhd2y ybcOtUIJuvly2XNBkNSs7E_ 7sArhoCOYcQAvD_BwE. Accessed September 7, 2020.

23. World Health Organization, 2020. Coronavirus. Geneva, Switzerland: WHO. Available at: https://www.who.int/health-topics/ coronavirus\#tab=tab_1. Accessed June 20, 2020. 
24. WebMD, 2020. What Are the Complications of Coronavirus (COVID19)? Available at: https://www.webmd.com/lung/coronaviruscomplications\#1. Accessed June 20, 2020.

25. European CDC, 2020. COVID-19 Pandemic. Available at: https:// www.ecdc.europa.eu/en/covid-19-pandemic. Accessed May $15,2020$.

26. CDC, 2020. Therapeutic Options for COVID-19 Patients CDC [Internet]. Available at: https://www.cdc.gov/coronavirus/2019ncov/hcp/therapeutic-options.html. Accessed June 20, 2020.

27. Khasawneh Al et al., 2020. Medical students and COVID-19: knowledge, attitudes, and precautionary measures. A descriptive study from Jordan. Front Public Health 8: 253.

28. White MS, Omer DM, Mohammad DGN, 2020. Knowledge, attitude and practice on prevention of airborne and droplet infections during the outbreak of corona virus among the college students in university of Bisha, Saudi Arabia. Int J Contemp Res Rev 11: 20773-20776.

29. Erfani A, Shahriarirad R, Ranjbar K, Mirahmadizadeh A, Moghadami M, 2020. Knowledge, attitude and practice toward the novel coronavirus (COVID-19) outbreak: a populationbased survey in Iran. Bull world Health organ. Available at: https://www.who.int/bulletin/online_first/COVID-19/en/.

30. CDC, 2020. Recommendation Regarding the Use of Cloth Face Coverings |CDC. Available at: https://www.cdc.gov/coronavirus/ 2019-ncov/prevent-getting-sick/cloth-face-cover.html. Accessed June 20, 2020.

31. CDC, 2020. Show Me the Science - How to Wash Your Hands Handwashing | CDC. Available at: https://www.cdc.gov/ handwashing/show-me-the-science-handwashing.html. Accessed June 20, 2020. 